\title{
Response Surface Methodology to Optimize Enzymatic Preparation of Deapio-Platycodin D and Platycodin D from Radix Platycodi
}

\author{
Wei Li ${ }^{1, \dagger}$, Li-Chun Zhao ${ }^{2, \dagger}$, Zi Wang ${ }^{1}$, Yi-Nan Zheng ${ }^{1}$, Jian Liang ${ }^{2, *}$ and Hui Wang ${ }^{3, *}$
}

1 College of Chinese Medicinal Materials, Jilin Agricultural University, Changchun 130118, China;

E-Mails: liwei7727@126.com (W.L.); wangzi8020@126.com (Z.W.);

zhenyinan@tom.com (Y.-N.Z.)

2 The Affiliated Ruikang Hospital of Guangxi Traditional Chinese Medical College,

Nanning 530011, China; E-Mail: hyzlc@ 126.com

3 China-Japan Union Hospital, Jilin University, Changchun 130033, China

$\dagger$ These authors contributed equally to this work.

* Authors to whom correspondence should be addressed; E-Mails: ljruikang@ 126.com (J.L.); hwangjlu@126.com (H.W.); Tel.: +86-771-2188589 (J.L.); +86-0431-85619922 (H.W.).

Received: 3 February 2012; in revised form: 8 March 2012 / Accepted: 19 March 2012 /

Published: 28 March 2012

\begin{abstract}
In the present work, we reported the enzymatic preparation of deapio-platycodin D (dPD) and platycodin D (PD) optimized by response surface methodology (RSM) from Radix Platycodi. During investigation of the hydrolysis of crude platycosides by various glycoside hydrolases, snailase showed a strong ability to transform deapio-platycoside $\mathrm{E}(\mathrm{dPE})$ and platycoside $\mathrm{E}(\mathrm{PE})$ into $\mathrm{dPD}$ and PD with $100 \%$ conversion. RSM was used to optimize the effects of the reaction temperature $\left(35-45{ }^{\circ} \mathrm{C}\right)$, enzyme load $(5-20 \%)$, and reaction time $(4-24 \mathrm{~h})$ on the conversion process. Validation of the RSM model was verified by the good agreement between the experimental and the predicted values of $\mathrm{dPD}$ and PD conversion yield. The optimum preparation conditions were as follows: temperature, $43{ }^{\circ} \mathrm{C}$; enzyme load, 15\%; reaction time, $22 \mathrm{~h}$. The biotransformation pathways were $\mathrm{dPE} \rightarrow \mathrm{dPD} 3 \rightarrow \mathrm{dPD}$ and $\mathrm{PE} \rightarrow \mathrm{PD} 3 \rightarrow \mathrm{PD}$, respectively. The determined method may be highly applicable for the enzymatic preparation of $\mathrm{APD}$ and PD for medicinal purposes and also for commercial use.
\end{abstract}


Keywords: snailase; deapio-platycodin D; platycodin D; radix platycodi; response surface methodology

\section{Introduction}

Radix Platycodi (Jiegeng in Chinese), the root of Platycodon grandiflorum A. DC (Campanulaceae), is frequently used in Asian countries as a traditional medicine. The major pharmacologically active components in Jiegeng are a class of oleanane-type triterpenoid saponins, more commonly known as platycosides. Until now, more than 30 were discovered and identified in $P$. grandiflorum, mainly including deapio-platycodin D (dPD) and platycodin D (PD) [1,2]. Figure 1 shows the chemical structures of platycosides studied in this paper. Among these platycosides, PD as a major platycoside and marker reference substance, exhibited strong cytotoxicity against tumor cell lines and can be implemented as a therapeutic agent for the treatment of cancer [3-6]. Therefore, there is great interest in the preparation of platycosides (mainly including dPD and PD) in terms of their bioactivities and commercial use[7,8].

Figure 1. Biotransformation pathway for production of deapio-platycodin D (5) and platycodin D (6): (a), indirectly, in this case dPE (1) and PE (2) converted to dPD (5) and PD (6) with an intermediate dPD3 (3) and PD3 (4); (b), directly, in this case dPE (1) and PE (2) converted to dPD (5) and PD (6) with any intermediates.
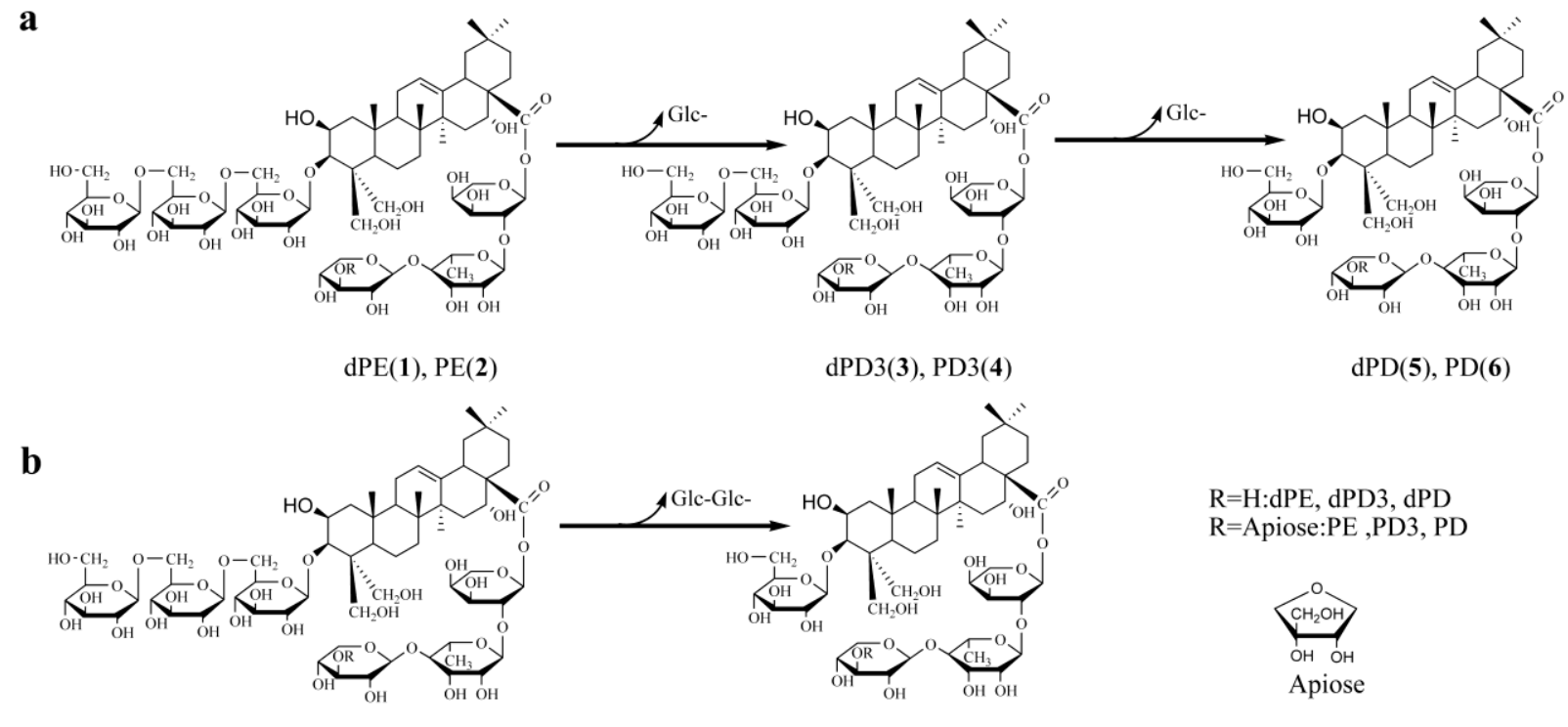

$\mathrm{dPD}(\mathbf{5}), \operatorname{PD}(\mathbf{6})$

$\mathrm{dPE}(\mathbf{1}), \operatorname{PE}(\mathbf{2})$

$\operatorname{dPD}(\mathbf{5}), \operatorname{PD}(\mathbf{6})$

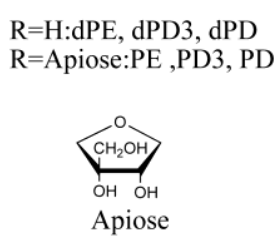

Recently, a variety of methods, including mild acid hydrolysis, alkali treatment and microbial conversion have been applied to the preparation of platycosides [9]. However, these chemical methods inevitably produced side-reactions and environmental pollution. Prior to this study, Aspergillus niger (A. niger) was used to convert platycosides, but these preparation processes were time-consuming, with low selectivity and low conversion rate [10]. As an alternative to the above preparation methods, enzymatic preparation (EP) has been implicated as the most promising for the preparation of active 
constituents via the selective hydrolysis of the sugar moieties, owing to its high specificity, yield and productivity [11-13]. Recently, snailase (a complex of cellulase, hemicellulase, pectinase and $\beta$-glucuronidase), extracted from the digestive tract of snails [14], have received increasing attention due to strong hydrolysis ability $[15,16]$. We have previously reported snailase effectively transformed 20(S)-protopanaxadiol-type ginsenosides to ginsenosides Rh1 via the cleavage of sugar moieties at the C-20 position [17]. During our investigations aiming to prepare large quantities of dPD and PD, snailase was found to be powerful for transforming $\mathrm{dPE}$ and PE to dPD and PD. Response surface methodology (RSM), an effective statistical technique, can use quantitative data to evaluate multiple parameters and their interactions by establishing a mathematical model [18,19]. Box-Behnken design (BBD), as one of the RSM designs, is more efficient and easier to arrange and interpret experiments in comparison with others, and widely applied in many studies [20,21]. Our research team has employed this technology for the extraction of chromones in Radix Saposhnikoviae [22].

The main objective of the present work was to investigate the feasibility of using enzymes in preparing $\mathrm{dPD}$ and PD via biotransformation of $\mathrm{dPE}$ and PE. To the best of our knowledge, snailase preparation of $\mathrm{dPD}$ and PD has not previously been published. Furthermore, the effects of reaction temperature, enzyme load, and reaction time on the enzymatic preparation efficiency and their interactions were also systemically analyzed for the first time using RSM and BBD methods.

\section{Results and Discussion}

\subsection{Selection of Glycolytic Enzymes}

To select enzymes for the concurrent bioconversion of platycosides in crude saponins to dPD and $\mathrm{PD}$, the hydrolyzing ability of several glycolytic enzymes based on the glycosidic moiety at C-3 position, snailase, $\beta$-glucanase, cellulase and amylase, was evaluated. Individual kinetics of hydrolysis of $50 \mathrm{mg} / \mathrm{mL}$ crude platycosides were investigated incubating each glycolytic enzyme at $37{ }^{\circ} \mathrm{C}$ for $24 \mathrm{~h}$. The enzyme amount was adjusted to $50 \mathrm{U} / \mathrm{g}$ of crude platycosides $(0.1 \mathrm{U} / \mathrm{mL})$. Although the above enzyme gave the same hydrolysis pattern and ability, complete hydrolysis to dPD and PD was only achieved in $24 \mathrm{~h}$ by snailase (data not shown). Therefore, snailase was selected for future investigations.

\subsection{Model Fitting}

After the preliminary ranges of the preparation variables were determined by one-factor-at-a-time experiments, the three independent variables, the reaction temperature $\left(X_{1}, 35-45{ }^{\circ} \mathrm{C}\right)$, enzyme load $\left(X_{2}, 5-20 \%\right)$ and reaction time $\left(X_{3}, 4-24 \mathrm{~h}\right)$, were fixed to optimize the yields of dPD and PD. The whole design consisted of 17 experimental points as listed in Table 1, and five replicates (run 13-17) at the center of the design were used to estimate an experimental error sum of squares. The triplicates were performed at all design points in randomized order. 
Table 1. Box-Behnken experimental design with the independent variables.

\begin{tabular}{cccccc}
\hline \multirow{2}{*}{ Run } & \multicolumn{2}{c}{ Coded variables levels } & \multicolumn{3}{c}{$\boldsymbol{Y}$ dPD and PD (mg/L) } \\
\cline { 2 - 6 } & $\begin{array}{c}\boldsymbol{X}_{\mathbf{1}}, \\
\text { Reaction temperature }\left({ }^{\circ} \mathbf{C}\right)\end{array}$ & $\begin{array}{c}\boldsymbol{X}_{\mathbf{2}}, \\
\text { Enzyme load }(\boldsymbol{\%})\end{array}$ & $\begin{array}{c}\boldsymbol{X}_{\mathbf{3}}, \\
\text { Reaction time (h) }\end{array}$ & Actual & Predicted \\
\hline 1 & $-1(35)$ & $-1(5.0)$ & $0(14)$ & 7.28 & 7.45 \\
2 & $1(45)$ & $-1(5.0)$ & $0(14)$ & 12.00 & 11.46 \\
3 & $-1(35)$ & $1(20)$ & $0(14)$ & 8.90 & 9.44 \\
4 & $1(45)$ & $1(20)$ & $0(14)$ & 13.22 & 13.05 \\
5 & $-1(35)$ & $0(12.5)$ & $-1(4)$ & 8.63 & 8.18 \\
6 & $1(45)$ & $0(12.5)$ & $-1(4)$ & 11.73 & 11.98 \\
7 & $-1(35)$ & $0(12.5)$ & $1(24)$ & 10.92 & 10.67 \\
8 & $1(45)$ & $0(12.5)$ & $1(24)$ & 14.02 & 14.48 \\
9 & $0(40)$ & $-1(5.0)$ & $-1(4)$ & 9.03 & 9.32 \\
10 & $0(40)$ & $1(20)$ & $-1(4)$ & 10.25 & 10.16 \\
11 & $0(40)$ & $-1(5.0)$ & $1(24)$ & 10.79 & 10.87 \\
12 & $0(40)$ & $1(20)$ & $1(24)$ & 13.89 & 13.60 \\
13 & $0(40)$ & $0(12.5)$ & $0(14)$ & 13.75 & 13.67 \\
14 & $0(40)$ & $0(12.5)$ & $0(14)$ & 13.08 & 13.67 \\
15 & $0(40)$ & $0(12.5)$ & $0(14)$ & 13.89 & 13.67 \\
16 & $0(40)$ & $0(12.5)$ & $0(14)$ & 13.89 & 13.67 \\
17 & $0(40)$ & $0(12.5)$ & $0(14)$ & 13.75 & 13.67 \\
\hline
\end{tabular}

As Table 2 shows, the analysis of variance (ANOVA) of conversion yield of dPD and PD indicated that experimental data had a determination coefficient $\left(R^{2}\right)$ of 0.977 with the calculated model with no significant lack of fit at $P>0.05$. That means that the calculated model was able to explain $97.7 \%$ of the results. The results indicated that the model used to fit response variables was significant $(P<0.0001)$ and adequate to represent the relationship between the response and the independent variables. $F$-test suggested that model had a very high model $F$-value $(F=33.43)$, indicating this model was highly significant. $R_{\text {adj }}^{2}$ value (adjusted determination coefficient) is the correlation measure for testing the goodness-of-fit of the regression equation [23]. The $R^{2}$ adj value of this model is 0.9880 , which indicated only $1.2 \%$ of the total variations were not explained by the model. Meanwhile, a relatively lower value of coefficient of variation $(C V=4.35)$ showed a better precision and reliability of the experiments carried out [24].

Table 2. Analysis of variance for the fitted quadratic polynomial model of enzymatic preparation of $\mathrm{dPD}$ and PD.

\begin{tabular}{ccccccc}
\hline Source & SS & DF & MS & $\boldsymbol{F}$-value & Prob $>\boldsymbol{F}$ & \\
\hline Model & 78.13 & 9 & 8.68 & 33.43 & $<0.0001$ & significant \\
Residual & 1.82 & 7 & 0.26 & & & \\
Lack of fit & 1.36 & 3 & 0.45 & 3.96 & 0.1086 & insignificant \\
Pure error & 0.46 & 4 & 0.11 & & & \\
\hline
\end{tabular}

SS, sum of squares; DF, degree of freedom; MS, mean square. 
It can be seen in Table 3 that conversion yield of dPD and PD was affected most significantly by reaction temperature $\left(X_{1}\right)(P<0.0001)$, followed by reaction time $\left(X_{3}\right)(P<0.0002)$ and enzyme load $\left(X_{2}\right)(P=0.0016)$. It was evident that all the quadratic parameters $\left(X_{1}^{2}, X_{2}^{2}, X_{3}{ }^{2}\right)$ were significant at the level of $P<0.05$ or $P<0.0001$, whereas all the interaction quadratic parameters were insignificant $(P>0.1)$. Predicted response $Y$ for the yield of dPD and PD could be expressed by the following second-order polynomial equation in terms of coded values.

$$
Y=-106.38+5.19 X_{1}+0.978 X_{2}+0.18 X_{3}-2.70 X_{1} X_{2}+5.24 X_{2} X_{3}-0.06 \times 10^{-3} X_{1}^{2}-0.03 X_{2}^{2}-5.92 X_{3}^{2}
$$

Where $Y$ is the yield of $\mathrm{dPD}$ and PD $(\mathrm{mg} / \mathrm{mL})$, and $X_{1}, X_{2}$ and $X_{3}$ are the coded variables for reaction temperature, enzyme load and reaction time, respectively.

Table 3. Estimated regression model of relationship between response variables (yield of dPD and PD) and independent variables $\left(X_{1}, X_{2}, X_{3}\right)$.

\begin{tabular}{cccccc}
\hline Variables & DF & SS & MS & $\boldsymbol{F}$-values & $\boldsymbol{p}$-value \\
\hline$X_{1}$ & 1 & 29.02 & 29.02 & 111.78 & $<0.0001$ \\
$X_{2}$ & 1 & 6.39 & 6.39 & 24.59 & 0.0016 \\
$X_{3}$ & 1 & 12.45 & 12.45 & 47.94 & 0.0002 \\
$X_{1} X_{2}$ & 1 & 0.041 & 0.041 & 0.16 & 0.7032 \\
$X_{1} X_{3}$ & 1 & 0.000 & 0.000 & 0.000 & 1.0000 \\
$X_{2} X_{3}$ & 1 & 0.89 & 0.89 & 3.43 & 0.1064 \\
$X_{1}^{2}$ & 1 & 9.39 & 9.39 & 36.17 & 0.0005 \\
$X_{2}^{2}$ & 1 & 14.11 & 14.11 & 54.34 & 0.0002 \\
$X_{3}^{2}$ & 1 & 3.06 & 3.06 & 11.80 & 0.0109 \\
\hline
\end{tabular}

\subsection{Analysis of Response Surface}

The regression equation was graphically represented by 3D response surface and 2D contour plots. From three dimensional response surface curves and contour plots shown in Figures 2-4, the effect of the independent variables and their mutual interaction on the yield of dPD and PD can be seen.

Figure 2. Response surface plot and contour plot of reaction temperature and enzyme load.
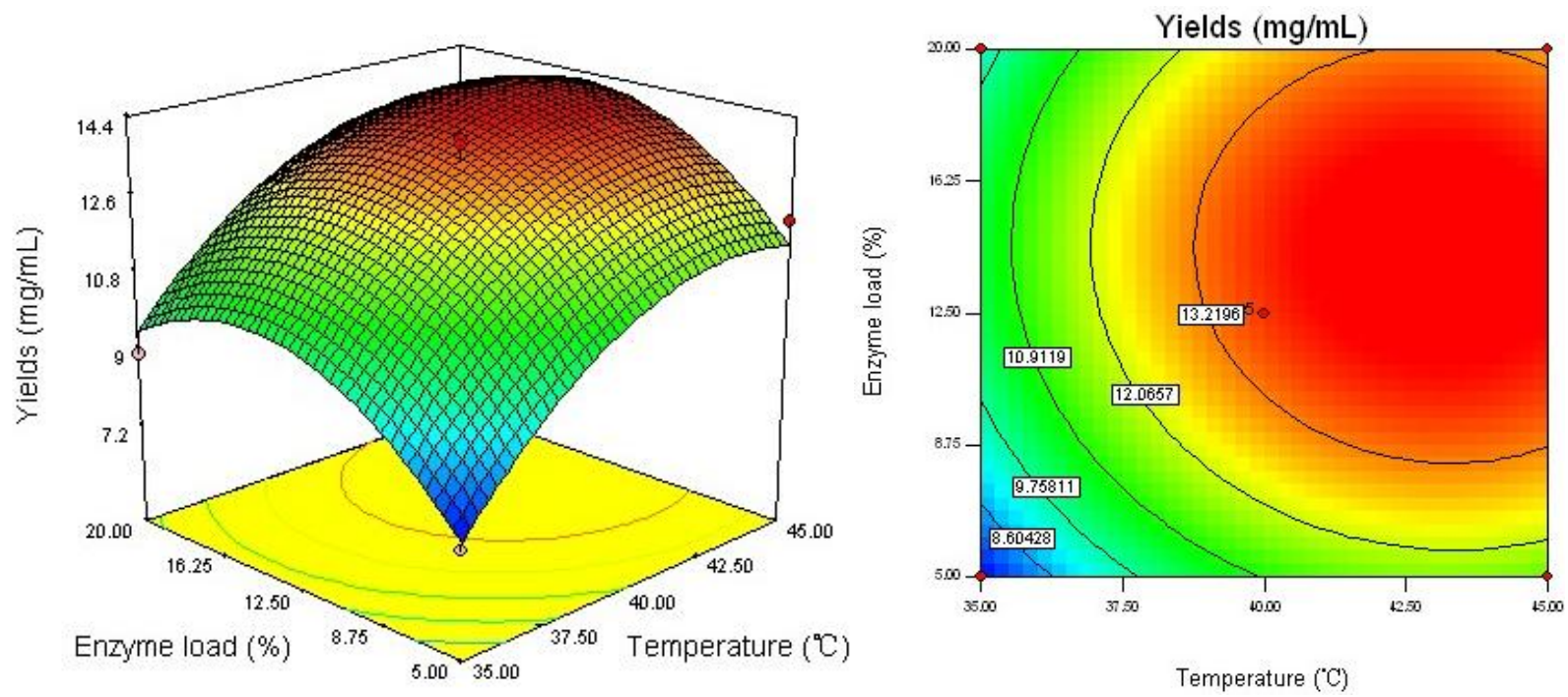
Figure 3. Response surface plot and contour plot of reaction temperature and reaction time.
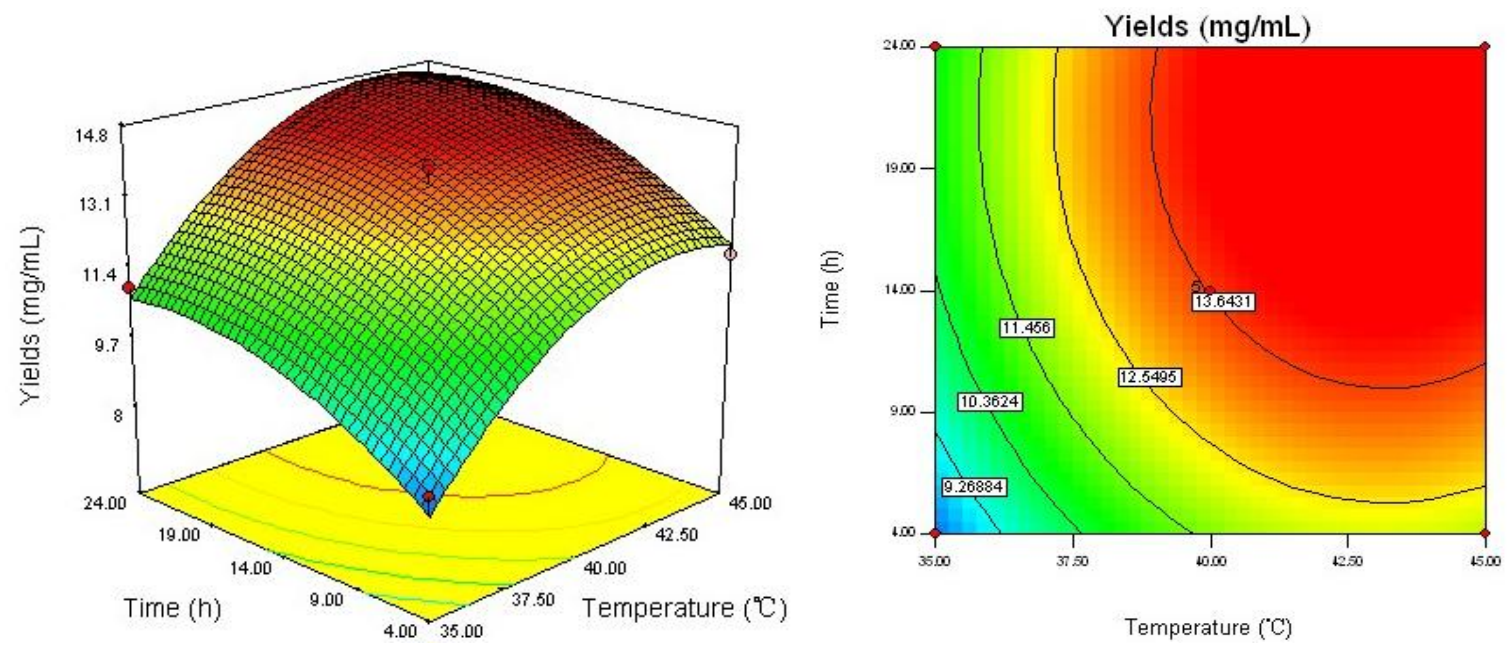

Figure 4. Response surface plot and contour plot of enzyme load and reaction time.
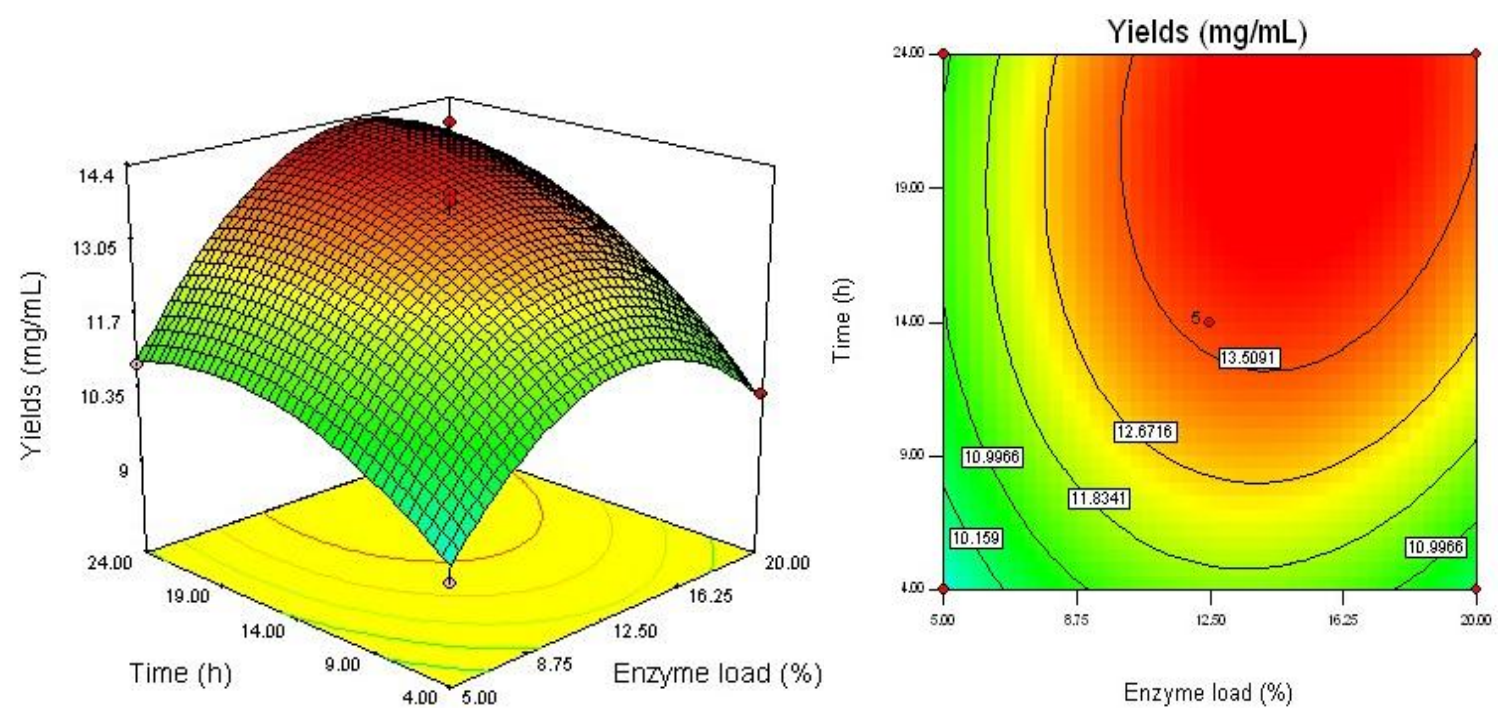

Figure 2 shows the interaction between reaction temperature $\left(X_{1}\right)$ and enzyme load $\left(X_{2}\right)$ on the yield of $\mathrm{dPD}$ and PD. Increase in reaction temperature from 35 to $45{ }^{\circ} \mathrm{C}$ with enzyme load from 5 to $20 \%$, enhanced the conversion yield of dPD and PD. While with increase of reaction temperature over $45{ }^{\circ} \mathrm{C}$ there was a gradual decline in the response and enzyme load over $20 \%$ did not show any obvious effect on the yield of $\mathrm{dPD}$ and PD. It could be explained that, increasing reaction temperature may enhance snailase activity in preparation process.

The effect of combination of reaction temperature $\left(X_{1}\right)$ and reaction time $\left(X_{3}\right)$ on the yield of dPD and PD is shown in Figure 3. It may be also observed that increase of reaction temperature from 35 to $45^{\circ} \mathrm{C}$ and reaction time from 4 to $22 \mathrm{~h}$, the yield of dPD and PD was increasing gradually. However, this interactive effect of reaction time with reaction temperature on the yield of dPD and PD was not very significant $(P=1.00)$.

As shown in Figure 4 and Table 3, the interaction of enzyme load $\left(X_{2}\right)$ and reaction time $\left(X_{3}\right)$ had a much weaker effect on the yield of dPD and PD $(P=0.1064)$. It depicted that the highest conversion yield could be achieved when using about $15 \%$ of enzyme load and $22 \mathrm{~h}$ of reaction time. However, 
the conversion yield did not increase with the enzyme load over 15\%. Moreover, $22 \mathrm{~h}$ of reaction time is enough for enzymatic preparation to convert all dPE and PE to dPD and PD.

\subsection{Optimal Conditions and Model Verification}

In this study, the aim of optimization was to find the conditions which gave the maximum conversion yield of $\mathrm{dPD}$ and PD. The software predicted the optimum reaction temperature, enzyme load and reaction time was $43.13{ }^{\circ} \mathrm{C}, 15 \%$ and $22.23 \mathrm{~h}$, respectively. The software predicted the yield of $\mathrm{dPD}$ and PD was $14.93 \mathrm{mg} / \mathrm{mL}$.

As shown in Table 4, three parallel experiments were carried out under the optimal conditions, and the average yield of $\mathrm{dPD}$ and PD was $14.81 \mathrm{mg} / \mathrm{mL}$. Compared with the value predicted by Design Expert 7.1.6, the results showed that the predicted value was very close to the actual results. This indicated that the optimization is reliable in the present study.

Table 4. Optimum conditions and the predicted and experimental value of response at the optimum conditions.

\begin{tabular}{lcccc}
\hline & $\begin{array}{c}\text { Reaction } \\
\text { temperature }\left({ }^{\circ} \mathbf{C}\right)\end{array}$ & $\begin{array}{c}\text { Enzyme load } \\
(\boldsymbol{\%})\end{array}$ & $\begin{array}{c}\text { Reaction time } \\
(\mathbf{h})\end{array}$ & $\begin{array}{c}\text { Yield of dPD and } \\
\text { PD (mg/mL) }\end{array}$ \\
\hline Optimum conditions & 43.13 & 15.00 & 22.23 & 14.93 (predicted) \\
Modified conditions & 43 & 15 & 22 & 14.81 (actual) \\
\hline
\end{tabular}

\subsection{LC/ESI-MS Analysis and Structures Elucidation}

Mass spectrometry, especially MS with electrospray ionization, is a valuable analytical tool in term of providing information on the molecular weights of polar and thermally labile compounds as saponins $[25,26]$.

Figure 5. ESI-MS spectra of deapio-platycodin D and platycodin D with $[\mathrm{M}-\mathrm{H}]^{-}$and $[\mathrm{M}+\mathrm{Na}]^{+}$ion.
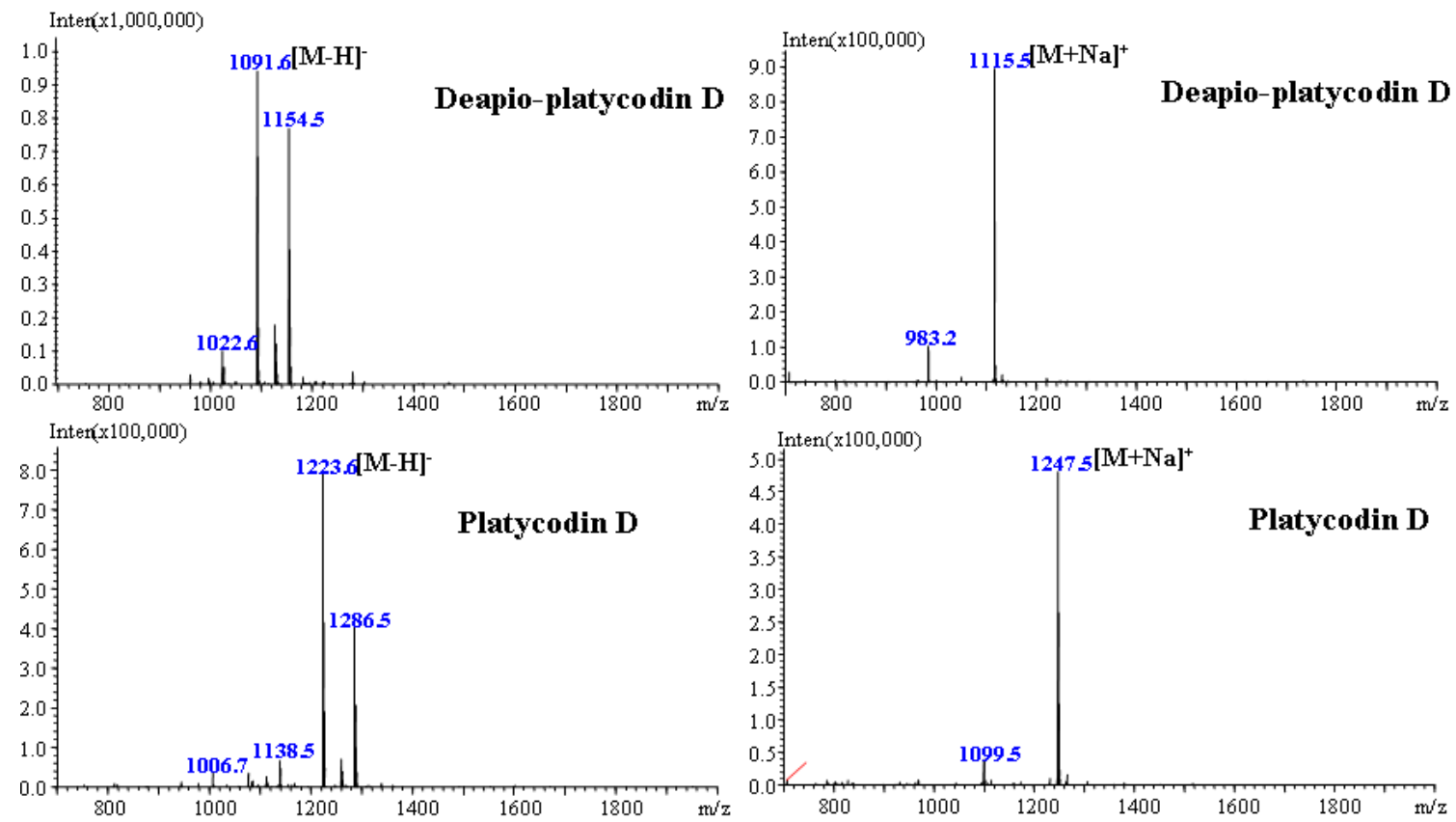
Identification of $\mathrm{APD}$ and PD were confirmed by LC/ESI-MS, comparing it with predominantly $[\mathrm{M}+\mathrm{Na}]^{+}$ion in the positive mode and $[\mathrm{M}-\mathrm{H}]^{-}$ion in the negative mode. In order to increase the signal-to-noise, $5 \mu \mathrm{M}$ of sodium acetate was added to the mobile phase to enhance the molecular ion intensity, and then the significantly increased $[\mathrm{M}+\mathrm{Na}]^{+}$ion was presented in the spectrum of ESI-MS. Meanwhile, a high abundance of $[\mathrm{M}-\mathrm{H}]^{-}$is observed in the negative mode. In the same manner, peaks at $m / z, 1115.5$ and 1247.5 in the positive spectrum and the peaks at $\mathrm{m} / \mathrm{z} 1091.6$ and 1223.6 in the negative spectrum (Figure 5) were assigned to known platycosides with molecular weight of 1092 and 1224 , respectively.

Finally, the structures of $\mathrm{dPD}$ and PD were elucidated on the basis of spectroscopic method including UV, IR, and ${ }^{13} \mathrm{C}-\mathrm{NMR}$. All the ${ }^{13} \mathrm{C}-\mathrm{NMR}$ data are in very good accordance to previously published references (data not shown) [27,28].

\section{Experimental Section}

\subsection{Plant Materials and Chemicals}

The roots of $P$. grandiflorum were purchased from Tong Ren Tang drugstore and identified by Professor Yinan Zheng. Its voucher specimen was deposited in College of Chinese Medicinal Material, Jilin Agricultural University. Snailase was purchased from Beijing Biodee Biotechnology Co., Ltd (http://www.biodee.net). $\beta$-glucanase, cellulase and amylase were supported by Ningxia Xiasheng Group Co., Ltd. (http://www.sunsonenzymes.com).

HPLC-grade acetonitrile and methanol were purchased from Fisher Chemicals (USA). Other chemicals for extraction and separation were all of analytical grade from Beijing Chemical Factory. Water was purified using a Milli-Q water purification system (Millipore, Bedford, MA, USA).

\subsection{Sample Preparation}

About $5.0 \mathrm{~kg}$ of powdered roots of Platycodi Radix was extracted with $70 \%$ ethanol by ultrasonic-assisted extraction for $0.5 \mathrm{~h}$ with 3 times. The combined extract was evaporated with a rotary evaporator under reduced pressure, suspended in water, and then partitioned with ethyl acetate and $n$-butanol. The $n$-butanol layer (crude platycosides, $85 \mathrm{~g}$ ) was evaporated, lyophilized, and stored in a desiccator until further use.

\subsection{Enzymatic Preparation of $d P D$ and PD from Crude Platycosides}

Snailase were incubated with crude platycosides in a $\mathrm{pH} 4.5$ sodium acetate buffer with agitation at different temperature (varying reaction temperature from 35 to $45{ }^{\circ} \mathrm{C}$ ) and different enzyme load (varying from 5 to 20\%) for certain time (varying reaction time from 4 to $24 \mathrm{~h}$ ). The mixtures were subsequently placed in a water bath at $90{ }^{\circ} \mathrm{C}$ to terminate the enzymatic reaction. The reaction mixtures were individually evaporated, dissolved in methanol, and filtered through a $0.45 \mu \mathrm{m}$ nylon filter membrane prior to injection into the HPLC system. The chromatographic peaks of six platycosides were confirmed by comparing their retention time with those of the reference standards. Quantification was carried out by the integration of the peak using external standard method. 


\subsection{HPLC Analysis of Platycosides}

The HPLC analysis was performed with a HPLC instrument (Agilent 1100, USA) equipped with a quaternary solvent delivery system, a column oven and UV detector. A HPLC method was developed using a reversed-phase C18 column (Hypersil ODS2, $250 \mathrm{~mm} \times 4.6 \mathrm{~mm}$ I.D., $5 \mu \mathrm{m}$ ). The column temperature was set at $30{ }^{\circ} \mathrm{C}$ and detection wavelength was set at $210 \mathrm{~nm}$. The mobile phase was consisted of water (A) and acetonitrile (B) with flow rate of $1.0 \mathrm{~mL} / \mathrm{min}$. The gradient elution was programmed as follows: 0-30 min, $18-22 \% \mathrm{~B} ; 30-60 \mathrm{~min}, 22-25 \% \mathrm{~B}$. The sample was dissolved in the methanol with $200 \mathrm{mg} / \mathrm{mL}$ of concentration. Then the $20 \mu \mathrm{L}$ of sample solution was directly injected into the chromatographic column manually. Three typical chromatograms of samples, before and after snailase preparation, are shown in Figure 6.

\subsection{LC/ESI-MS Analysis}

The platycosides were analyzed by a LC/ESI-MS instrument from Shimadzu consisting of a Surveyor MS pump and UV detector. The mass spectrometer was equipped with an electrospray ion (ESI) source operated in positive and negative mode. All of trap analyzer parameters were optimized and set as follow: capillary voltage of $4.5 \mathrm{kV}$, cone voltage of $45 \mathrm{~V}$, source temperature of $100{ }^{\circ} \mathrm{C}$, desolvation temperature of $250^{\circ} \mathrm{C}$, and $\mathrm{N}_{2}$ sheath gas of $90 \mathrm{~L} / \mathrm{h}$. The inject volume of sample was $5.0 \mu \mathrm{L}$.

Figure 6. HPLC chromatograms of enzymatic preparation samples for $0 \mathrm{~h}(\mathbf{A}), 5 \mathrm{~h}(\mathbf{B})$, and $24 \mathrm{~h}(\mathbf{C})$. Column: Hypersil ODS2 (250 $\mathrm{mm} \times 4.6 \mathrm{~mm}$, I.D., $5 \mu \mathrm{m})$; mobile phase: acetonitrile-water (Acetonitrile: 0-30 $\mathrm{min}, 18-22 \%$; 30-60 min, 22-25\%); flow rate: $1.0 \mathrm{~mL} / \mathrm{min}$; detection wavelength: $210 \mathrm{~nm}$. Key to peak identity: 1, dPE; 2, PE; 3, dPD3; 4, PD3; 5, dPD; 6, PD.

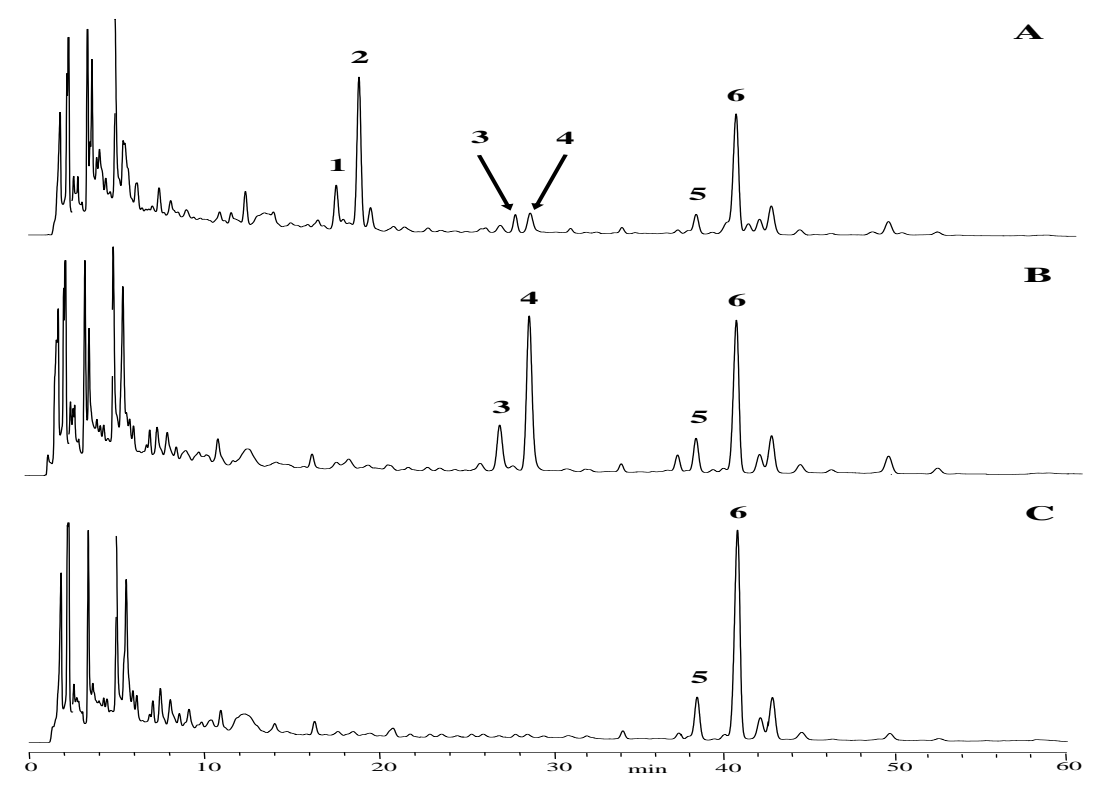

\subsection{Experimental Design}

In the present investigation, we employed the software Design Expert (Trial Version 7.1.6, Stat-Ease Inc., Minneapolis, MN) for experimental design, data analysis and model building. A 
Box-Behnken design (BBD) with three variables was used to determine the response pattern and then to establish a model.

Experimental data were fitted to a quadratic polynomial model and regression coefficient obtained. The non-linear computer-generated quadratic model used in the response surface was as follow:

$$
Y=\beta_{0}+\sum_{j=1}^{k} \beta_{j} X_{j}+\sum_{j=1}^{k} \beta_{j j} X_{j}^{2}+\sum \sum_{i<j} \beta_{i j} X_{i} Y_{j}
$$

where $Y$ is the estimated response, $\beta_{0}, \beta_{j}, \beta_{j j}$ and $\beta_{i j}$ are the regression coefficients for intercept, linearity, square and interaction, respectively, while $X_{i}, X_{j}$ are the independent coded variables.

\subsection{Data Analysis}

Data were expressed as standard errors of the means (SEM) of three replicated determinations. The response obtained from each set of experimental design (Table 1) was subjected to multiple non-linear regressions using the Design Expert software. The quality of the fit of the polynomial model equation was expressed by the coefficient were checked by $F$-test and $p$-value.

\section{Conclusions}

In this paper, the conditions for enzymatic preparation of deapio-platycodin $\mathrm{D}$ and platycodin $\mathrm{D}$ from Radix Platycodi were optimized by using RSM and BBD. The results demonstrated that the change of reaction temperature, enzyme load and reaction time could significantly affect the yields of $\mathrm{dPD}$ and PD. The estimated models were able to indicate preparation conditions, allowing superior conversion yield. The highest yields predicted for $\mathrm{APD}$ and PD could be attained at optimal conditions including $43{ }^{\circ} \mathrm{C}$ of reaction temperature, $15 \%$ of enzyme load and $22 \mathrm{~h}$ of reaction time. Thus, this methodology could provide an example for a model to examine the non-linear nature between independent variables and responses in a short-term experiment.

\section{Acknowledgments}

The authors acknowledge support for this work from Jilin Science \& Technology Development Plan (201201102; 20100938) and The Initial Funding of Jilin Agricultural University for Young Scholars (2009B)

\section{References}

1. Li, W.; Zhang, W.; Xiang, L.; Wang, Z.; Zheng, Y.N.; Wang, Y.P.; Zhang, J.; Chen, L. Platycoside N: A new oleanane-type triterpenoid saponin from the roots of Platycodon grandiflorum. Molecules 2010, 15, 8702-8708.

2. Xie, Y.; Sun, H.X.; Li, D. Platycodin D is a potent adjuvant of specific cellular and humoral immune responses against recombinant hepatitis B antigen. Vaccine 2009, 27, 757-764.

3. Kim, M.O.; Moon, D.O.; Choi, Y.H.; Shin, D.Y.; Kang, H.S.; Choi, B.T.; Lee, J.D.; Li, W.; Kim, G.Y. Platycodin D induces apoptosis and decreases telomerase activity in human leukemia cells. Cancer Lett. 2008, 261, 98-107. 
4 Yu, J.S.; Kim, A.K. Platycodin D induces apoptosis in MCF-7 human breast cancer cells. J. Med. Food. 2010, 13, 298-305.

5. Ahn, K.S.; Hahn, B.S.; Kwack, K.; Lee, E.B.; Kim, Y.S. Platycodin D-induced apoptosis through nuclear factor-kappaB activation in immortalized keratinocytes. Eur. J. Pharmacol. 2006, 537, $1-11$.

6. Shin, D.Y.; Kim, G.Y.; Li, W.; Choi, B.T.; Kim, N.D.; Kang, H.S.; Choi, Y.H. Implication of intracellular ROS formation; caspase-3 activation and Egr-1 induction in platycodin D-induced apoptosis of U937 human leukemia cells. Biomed. Pharmacother. 2009, 63, 86-94.

7. Jeong, E.K.; Cha, H.J.; Ha, Y.W.; Kim, Y.S.; Ha, I.J.; Na, Y.C. Development and optimization of a method for the separation of platycosides in Platycodi Radix by comprehensive two-dimensional liquid chromatography with mass spectrometric detection. J. Chromatogr. A 2010, 1217, 4375-4382.

8. Ha, I.J.; Ha, Y.W.; Kang, M.; Lee, J.; Park, D.; Kim, Y.S. Enzymatic transformation of platycosides and one-step separation of platycodin D by high-speed countercurrent chromatography. J. Sep. Sci. 2010, 33, 1916-1922.

9. Ha, Y.W.; Kim, Y.S. Preparative isolation of six major saponins from Platycodi Radix by high-speed counter-current chromatography. Phytochem. Anal. 2009, 20, 207-213.

10. Wie, H.J.; Zhao, H.L.; Chang, J.H.; Kim, Y.S.; Hwang, I.K.; Ji, G.E. Enzymatic modification of saponins from Platycodon grandiflorum with Aspergillus niger. J. Agric. Food Chem. 2007, 55, 8908-8913.

11. Park, J.S.; Rho, H.S.; Kim, D.H.; Chang, I.S. Enzymatic preparation of kaempferol from green tea seed and its antioxidant activity. J. Agric. Food Chem. 2006, 54, 2951-2956.

12. Ko, S.R.; Choi, K.J.; Suzuki, K.; Suzuki, Y. Enzymatic preparation of ginsenosides Rg2, Rh1, and F1. Chem. Pharm. Bull. 2003, 51, 404-408.

13. Ko, S.R.; Suzuki, Y.; Choi, K.J.; Kim, Y.H. Enzymatic preparation of genuine prosapogenin, 20(S)-ginsenoside Rh1, from ginsenosides Re and Rg1. Biosci. Biotechnol. Biochem. 2000, 64, 2739-2743.

14. Liu, X.; Cui, Y.; Yang, L.; Yang, S.L. Purification of a ginsenoside-Rb1 hydrolase from Helix snailase (in Chinese). Sheng Wu Gong Cheng Xue Bao 2005, 21, 929-933.

15. You, J.Y.; Peng, C.; Liu, X.; Ji, X.J.; Lu, J.; Tong, Q.; Wei, P.; Cong, L.; Li, Z.; Huang, H. Enzymatic hydrolysis and extraction of arachidonic acid rich lipids from Mortierella alpina. Bioresour. Technol. 2011, 102, 6088-6094.

16. He, K.; Liu, Y.; Yang, Y.; Li, P.; Yang, L. A dammarane glycoside derived from ginsenoside Rb3. Chem. Pharm. Bull. 2005, 53, 177-179.

17. Hou, J.; Li, W.; Zheng, Y. Determination and enzymolysis preparation of ginsenoside Rh1 (in Chinese). Zhongguo Zhong Yao Za Zhi 2009, 34, 3030-3033.

18. Bai, X.L.; Yue, T.L.; Yuan, Y.H.; Zhang, H.W. Optimization of microwave-assisted extraction of polyphenols from apple pomace using response surface methodology and HPLC analysis. J. Sep. Sci. 2010, 33, 3751-3758.

19. Zhou, Y.; Fung-Kei, C.F.; He, Z.Z.; Song, J.Z.; Qiao, C.F.; Liu, X.; Ding, L.S.; Gesang, S.L.; $\mathrm{Xu}$, H.X. Optimisation of ultra-performance LC conditions using response surface methodology 
for rapid separation and quantitative determination of phenolic compounds in Artemisia minor. J. Sep. Sci. 2010, 33, 3675-3682.

20 Ferreira, S.L.; Bruns, R.E.; Ferreira, H.S.; Matos, G.D.; David, J.M.; Brandao, G.C.; da Silva, E.G.; Portugal, L.A.; dos Reis, P.S.; Souza, A.S. Box-Behnken design: an alternative for the optimization of analytical methods. Anal. Chim. Acta 2007, 597, 179-186.

21. Lahlali, R.; Massart, S.; Serrhini, M.N.; Jijakli, M.H. A Box-Behnken design for predicting the combined effects of relative humidity and temperature on antagonistic yeast population density at the surface of apples. Int. J. Food Microbiol. 2008, 122, 100-108.

22. Li, W.; Wang, Z.; Sun, Y.S.; Chen, L.; Han, L.K.; Zheng, Y.N. Application of response surface methodology to optimise ultrasonic-assisted extraction of four chromones in Radix Saposhnikoviae. Phytochem. Anal. 2011, 22, 313-321.

23. Liu, W.; Yu, Y.; Yang, R.; Wan, C.; Xu, B.; Cao, S. Optimization of total flavonoid compound extraction from Gynura medica leaf using response surface methodology and chemical composition analysis. Int. J. Mol. Sci. 2010, 11, 4750-4763.

24. Zhang, L.L.; Xu, M.; Wang, Y.M.; Wu, D.M.; Chen, J.H. Optimizing ultrasonic ellagic acid extraction conditions from infructescence of Platycarya strobilacea using response surface methodology. Molecules 2010, 15, 7923-7932.

25. Yan, B.; Wang, G.; A, J.; Xie, L.; Hao, H.; Liang, Y.; Sun, J.; Li, X.; Zheng, Y. Construction of the fingerprints of ginseng stem and leaf saponin reference substances and spiked plasma sample by LC-ESI/MS and its application to analyzing the compounds absorbed into blood after oral administration of ginseng stem and leaf saponin in rat. Biol. Pharm. Bull. 2007, 30, 1657-1662.

26. Li, K.; Ding, L.; Yang, Z.L.; Liu, E.H.; Qi, L.W.; Li, P.; Hu, Y.Z. Determination of asperosaponin VI in rat plasma by HPLC-ESI-MS and its application to preliminary pharmacokinetic studies. Biomed. Chromatogr. 2010, 24, 550-555.

27. Fu, W.W.; Shimizu, N.; Dou, D.Q.; Takeda, T.; Fu, R.; Pei, Y.H.; Chen, Y.J. Five new triterpenoid saponins from the roots of Platycodon grandiflorum. Chem. Pharm. Bull. 2006, 54, 557-560.

28. Kim, Y.S.; Kim, J.S.; Choi, S.U.; Kim, J.S.; Lee, H.S.; Roh, S.H.; Jeong, Y.C.; Kim, Y.K.; Ryu, S.Y. Isolation of a new saponin and cytotoxic effect of saponins from the root of Platycodon grandiflorum on human tumor cell lines. Planta Med. 2005, 71, 566-568.

(C) 2012 by the authors; licensee MDPI; Basel; Switzerland. This article is an open access article distributed under the terms and conditions of the Creative Commons Attribution license (http://creativecommons.org/licenses/by/3.0/). 